\title{
Risk factors for radiological hip involvement in patients with ankylosing spondylitis
}

\author{
Shijun Chen ${ }^{1} \oplus$, Lei Deng ${ }^{1 *}$ (1)
}

\section{SUMMARY}

OBJECTIVE: Our study aimed to explore the potential risk factors for radiological hip joint involvement in patients with ankylosing spondylitis (AS).

METHODS: This cross-sectional convey collected the clinical data, laboratory indicators, and radiographic data of patients with AS. Radiographic hip joint involvement was defined as a Bath Ankylosing Spondylitis Radiology Hip Index (BASRI-hip) score $\geq 2$. Multivariate logistic regression analyses were conducted to explore the potential risk factors for radiological hip involvement in patients with AS.

RESULTS: Based on BASRI-hip score, all enrolled 386 patients with AS were classified as patients involving with radiological hip joint involvement (BASRI-hip $\geq 2 ; n=203$ ) and those without it (BASRI-hip $\leq 1 ; n=183$ ). Mean age of enrolled patients with AS were $36.7 \pm 11.9$ years, and 320 (82.9\%) patients were male. Mean course of disease was $10.7 \pm 8.3$ years, and 349 (90.4\%) patients were with a positive HLAB27. Multivariate analyses indicated that Juvenile onset (onset age $\leq 16$ years) (odds ratio $[O R]=4.159,95 \%$ confidence interval [Cl], 1.779-9.721, $\mathrm{p}<0.001)$, body mass index $(\mathrm{BMI})<18.5 \mathrm{~kg} / \mathrm{m}^{2}(\mathrm{OR}=1.986,95 \% \mathrm{Cl} 1.187-3.323, \mathrm{p}=0.009)$, continuous nonsteroidal anti-inflammatory drug (NSAID) use (OR=0.351, 95\% $\mathrm{Cl} 0.155-0.794, \mathrm{p}=0.012)$, and bone mass below the expected range for age $(Z$ score $\leq-2)(O R=2.791,95 \% \mathrm{Cl} 1.456-5.352, p=0.002)$ were independently associated with radiological hip joint involvement in patients with AS.

CONCLUSIONS: The potential risk factors for radiological hip joint involvement were juvenile onset, lower BMI, and bone mass below the expected range for age. Furthermore, continuous NSAID use was the protective factor for radiological hip joint involvement in these population.

KEYWORDS: Radiological hip involvement. Ankylosing spondylitis. Nonsteroidal anti-inflammatory drugs. Bone density.

\section{INTRODUCTION}

Ankylosing spondylitis (AS) is a chronic inflammatory rheumatic disease that mainly damages the vertebral column and sacroiliac joints. AS has an incidence rate of $0.5-1.0 \%$ and is more common in young men. Clinical features of patients with AS include inflammatory back pain, asymmetrical peripheral oligoarthritis, enthesitis, and specific organ involvement such as anterior uveitis, psoriasis, and chronic inflammatory bowel disease ${ }^{1}$.

Previous study reports that about $25-33 \%$ patients with AS experience hip joint involvement ${ }^{2}$. The hip joint is one of the most stable joints, which is also the largest weight-bearing joint in the human body and is crucial to sustain balance and body posture. Damage of hip joint is a major cause of disability in patients with $\mathrm{AS}^{3}$. The diagnosis of hip joint involvement in patients with AS is reliable on clinical symptoms, joint malfunctioning, and findings from $\mathrm{X}$-ray and/or magnetic resonance imaging. The Bath Ankylosing Spondylitis Radiology Hip Index (BASRI-hip) score based on X-ray is commonly applied in the studies of radiological hip involvement in patients with AS. Finally, almost $5 \%$ patients with AS require total hip replacement or hip arthroplasty ${ }^{4}$.

\footnotetext{
${ }^{1}$ Ankang Central Hospital, Department of Hematology and Rheumatology - Shaanxi Province, China.

*Corresponding author: denglei_flower@outlook.com

Conflicts of interest: the authors declare there is no conflicts of interest. Funding: none.

Received on June 27, 2021. Accepted on July 18, 2021.
} 
Remarkably, the factors associated with radiological hip joint involvement in patients with AS have not been extensively explored. The progression speed and severity of hip joint involvement in patients with AS are related to individual variations ${ }^{5}$. It is crucial to screen the potential factors that are related to the occurrence, progression, and severity of hip joint damage in these patients, and the optimal treatment and management plans could be conducted to prevent or postpone the deterioration of hip joint to the end stage. Currently, limited data are available on the factors associated with radiographic changes of hip joint damage in patients with AS. Herein, we aimed to explore the potential risk factors of radiological hip involvement in patients with AS, which could help screen the specific patients who might require a close follow-up or hip replacement surgery.

\section{METHODS}

\section{Patients}

This was a cross-sectional study of patients with AS treated at the Department of Hematology and Rheumatology of Ankang Central Hospital between May 2014 and July 2020. Inclusion criteria were (1) aged ${ }^{3} 18$ years with a diagnosis of AS according to the modified New York criteria for classification of AS developed in 1984 and (2) course of disease ${ }^{3} 1$ year. Exclusion criteria were (1) gouty arthritis, infectious arthritis, or rheumatoid arthritis; (2) cancerous bone tumors, bone metastasis, or hematological malignancies; and (3) incomplete medical records. The study was approved by the Ethics Committee of Ankang Central Hospital, and informed consent of patient was waived by the Ethics Committee due to the retrospective nature of the study design.

\section{Data collection}

Clinical data were collected from all patients, including age, sex, age of disease onset, course of disease, family AS history, smoking history, body mass index (BMI), and treatment agents (anti-tumor necrosis factor [TNF], nonsteroidal anti-inflammatory drugs [NSAIDs], sulfasalazine, methotrexate, thalidomide, and glucocorticoids). Clinical examinations were performed to record peripheral arthritis, iritis, and results of Schober's test. The Bath Ankylosing Spondylitis Functional Index (BASFI) and Bath Ankylosing Spondylitis Disease Activity Index (BASDAI) were used to assess the functional status, hip function, and disease activity. The laboratory indicators of ESR, CRP, and the HLA-B27 status were recorded and evaluated in all patients. The application of calcaneal quantitative ultrasound was conducted to determine bone mass through an Ultrasonic bone intensity meter (GE Healthcare, Waukesha, WI, USA). The Z value of -2.0 or lower is defined as the bone mass below the expected range for age.

\section{Outcomes}

The BASRI-hip (0-4 points) was used to evaluate radiographic hip joint involvement ${ }^{6}$, which was a reliable tool for grading hip joint radiographic changes in patients with AS. It was classified as follows: $0=$ normal (no damage, no radiological hip joint change); $1=$ suspicious damage (potential focal joint space narrowing), $2=$ mild (obvious hip joint lesion but circumferential joint space narrowing $>2 \mathrm{~mm}$ ); $3=$ moderate (definite hip joint lesion, circumferential joint space narrowing $\leq 2 \mathrm{~mm}$, or boneon-bone apposition of $\leq 2 \mathrm{~cm}$ ); and $4=$ severe (bone deformity or bone-on-bone apposition of $<2 \mathrm{~cm}$ or indication for total hip replacement). Radiographic hip joint involvement was defined as a BASRI-hip score ${ }^{3} 2$.

\section{Statistical analysis}

Continuous data were expressed as mean \pm standard deviation or median (interquartile range $[\mathrm{IQR}]$ ) and compared using the Student's t-test or the Mann-Whitney U test. Categorical data were presented as proportion and analyzed with the chi-square test or Fisher's exact test. Univariable and multivariable logistic regression analyses were performed to identify the factors associated with radiological hip joint. Variables with $\mathrm{p}<0.1$ in the univariable analyses were included in the multivariable analysis. SPSS version 22.0 (IBM, Armonk, NY, USA) was performed for all analyses, and a two-sided $\mathrm{p}<0.05$ indicated statistical significance.

\section{RESULTS}

\section{Patients' characteristics}

A total of 386 patients with AS were finally analyzed. Based on BASRI-hip score, there were 203 patients with radiological hip joint involvement and 183 patients without it. The mean age was $36.7 \pm 11.9$ years, and $320(82.9 \%)$ patients were males. The mean course of disease was $10.7 \pm 8.3$ years, and the mean BMI was $10.7 \pm 8.3 \mathrm{~kg} / \mathrm{m}^{2}$. Eighty (20.7\%) patients had the juvenile onset. There were $349(90.4 \%)$ patients with a positive HLAB27, and 35 (9.1\%) patients were combined with iritis. The median value of BASDAI was 3.5 (IQR, 2.3-5.5) and that of BASFI was 3.2 (IQR, 1.1-5.6). In addition, 58 $(15.0 \%)$ patients had received TNF blockers $>3$ months, and $70(18.1 \%)$ patients were treated with continuous use of NSAIDs. The baseline clinical characteristics are indicated in Table 1. 
Table 1. Baseline data of all enrolled patients with ankylosing spondylitis.

\begin{tabular}{|c|c|}
\hline & All patients $(n=386)$ \\
\hline Age (years), mean $\pm S D$ & $36.7 \pm 11.9$ \\
\hline Sex (male), n (\%) & $320(82.9)$ \\
\hline $\mathrm{BMI}\left(\mathrm{kg} / \mathrm{m}^{2}\right)$, mean $\pm \mathrm{SD}$ & $23.1 \pm 4.2$ \\
\hline Juvenile onset (onset age $\leq 16$ years), n (\%) & $80(20.7)$ \\
\hline Course of disease (years), mean $\pm S D$ & $10.7 \pm 8.3$ \\
\hline Smoking history, n (\%) & $192(49.7)$ \\
\hline Family AS history, n (\%) & $57(14.8)$ \\
\hline $\mathrm{CRP}(\mathrm{mg} / \mathrm{dL})$, median (Q1-Q3) & $23.0(10.9-55.2)$ \\
\hline ESR (mm/h), median (Q1-Q3) & $42(17-64)$ \\
\hline HLAB27 positive, n (\%) & $349(90.4)$ \\
\hline Iritis, n (\%) & $35(9.1)$ \\
\hline Achilles tendinitis, n (\%) & $55(14.2)$ \\
\hline Peripheral arthritis, n (\%) & $177(45.9)$ \\
\hline Schober's test positive, n (\%) & $190(49.2)$ \\
\hline Bone mass below the expected range for age (Z score $\leq-2)$, $n(\%)$ & $102(26.4)$ \\
\hline BASDAl, median (Q1-Q3) & $3.5(2.3-5.5)$ \\
\hline BASFI, median (Q1-Q3) & $3.2(1.1-5.6)$ \\
\hline TNF blockers >3 months, n (\%) & $58(15.0)$ \\
\hline Continuous NSAIDs use, n (\%) & $70(18.1)$ \\
\hline SSZ >6 months, n (\%) & $96(24.9)$ \\
\hline MTX >6 months, n (\%) & $40(10.4)$ \\
\hline Thal >6 months, $\mathrm{n}(\%)$ & $31(8.0)$ \\
\hline Glucocorticoid >2 weeks, n (\%) & $38(9.8)$ \\
\hline
\end{tabular}

SD: standard deviation; BMI: body mass index; AS: ankylosing spondylitis; CRP: C-reactive protein; ESR: erythrocyte sedimentation rate; BASDAI: bath ankylosing spondylitis disease activity index; BASFI: bath ankylosing spondylitis functional index; TNF: tumor necrosis factor; NSAIDs: nonsteroidal antiinflammatory drugs; SSZ: sulfasalazine; MTX: methotrexate; Thal: thalidomide.

\section{Univariable analyses}

Univariate analysis revealed that compared to patients without radiological hip joint involvement, those with radiological hip joint involvement were younger (unadjusted odds ratio $[\mathrm{OR}]=0.868,95 \%$ confidence interval $[\mathrm{CI}]$ : $0.812-0.928, \mathrm{p}<0.001)$, had the higher proportions of BMI $<18.5 \mathrm{~kg} / \mathrm{m}^{2}$ (unadjusted OR=4.387, 95\%CI $1.968-9.779$, $\mathrm{p}<0.001$ ), juvenile onset (unadjusted $\mathrm{OR}=4.297,95 \% \mathrm{CI}$ 2.082-8.868, $\mathrm{p}<0.001$ ), bone mass below the expected range for age ( $\mathrm{Z}$ score $\leq-2)$ (unadjusted $\mathrm{OR}=3.361,95 \% \mathrm{CI}$ 1.682-6.717, $\mathrm{p}<0.001)$, and TNF blockers $>3$ months (unadjusted OR=2.614, 95\%CI 1.092-6.259, $\mathrm{p}=0.031$ ), and the results are indicated in Table 2.

\section{Multivariable analyses}

Multivariate regression analysis of potential factors associated with radiological hip joint involvement is presented in Table 3. After adjusting for potential confounding factors $(<0.1$ in the univariable analyses was included in the multivariable analysis), the results indicated that juvenile onset (adjusted $\mathrm{OR}=4.159$, 95\%CI 1.779-9.721, $\mathrm{p}=0.001$ ), BMI $<18.5 \mathrm{~kg} / \mathrm{m}^{2}$ (adjusted $\mathrm{OR}=1.986,95 \% \mathrm{CI} 1.187-3.323, \mathrm{p}=0.009)$, continuous NSAIDs use (adjusted OR=0.351, 95\%CI 0.155-0.794, $\mathrm{p}=0.012$ ), bone mass below the expected range for age ( $Z$ score $\leq-2)$ (adjusted $\mathrm{OR}=2.791,95 \% \mathrm{CI} 1.456-5.352, \mathrm{p}=0.002$ ), and BASFI (adjusted $\mathrm{OR}=1.382,95 \% \mathrm{CI} 1.097-1.741, \mathrm{p}=0.006$ ) were independently associated with radiological hip joint involvement. 
Table 2. Multivariate regression analysis of potential factors associated with radiological hip joint involvement (defined as a bath ankylosing spondylitis radiology hip index score $\geq 2$ ).

\begin{tabular}{|c|c|c|c|c|c|}
\hline & $\begin{array}{l}\text { BASRI-hip } \leq 1 \\
(\mathrm{n}=183)\end{array}$ & $\begin{array}{l}\text { BASRI-hip } \geq 2 \\
(\mathrm{n}=203)\end{array}$ & $p$ & Unadjusted OR & $95 \% \mathrm{Cl}$ \\
\hline Age (years), mean $\pm S D$ & $39.2 \pm 11.3$ & $31.2 \pm 10.6$ & $<0.001$ & 0.868 & $0.812-0.928$ \\
\hline Sex (male), n (\%) & $145(79.2)$ & $175(86.2)$ & 0.071 & 1.547 & $0.965-2.385$ \\
\hline $\mathrm{BMI}<18.5 \mathrm{~kg} / \mathrm{m}^{2}, \mathrm{n}(\%)$ & $13(7.1)$ & $51(25.1)$ & $<0.001$ & 4.387 & $1.968-9.779$ \\
\hline $\begin{array}{l}\text { Juvenile onset (onset age } \leq 16 \\
\text { years), } \mathrm{n}(\%)\end{array}$ & $19(10.4)$ & $61(30.0)$ & $<0.001$ & 4.297 & $2.082-8.868$ \\
\hline $\begin{array}{l}\text { Course of disease (years), } \\
\text { mean } \pm \text { SD }\end{array}$ & $10.2 \pm 7.5$ & $10.8 \pm 8.8$ & 0.512 & 0.954 & $0.829-1.098$ \\
\hline Smoking history, $\mathrm{n}(\%)$ & $84(45.9)$ & $108(53.2)$ & 0.155 & 1.479 & $0.862-2.536$ \\
\hline Family AS history, n (\%) & $32(17.5)$ & $25(12.3)$ & 0.151 & 0.627 & $0.332-1.186$ \\
\hline CRP (mg/dL), median (Q1-Q3) & $20.7(9.5-53.8)$ & $24.9(11.6-55.1)$ & 0.713 & 1.091 & $0.686-1.735$ \\
\hline ESR (mm/h), median (Q1-Q3) & $36(17-62)$ & $42(25-64)$ & 0.312 & 1.109 & $0.907-1.355$ \\
\hline HLAB27 positive, n (\%) & $165(90.2)$ & $184(90.6)$ & 0.871 & 1.071 & $0.468-2.451$ \\
\hline Iritis, n (\%) & $11(6.0)$ & $24(11.8)$ & 0.055 & 2.213 & $0.983-4.981$ \\
\hline Achilles tendinitis, n (\%) & $25(13.7)$ & $30(14.8)$ & 0.757 & 0.764 & $0.139-4.204$ \\
\hline Peripheral arthritis, n (\%) & $80(43.7)$ & $97(47.8)$ & 0.427 & 1.197 & $0.768-1.865$ \\
\hline Schober's test positive, n (\%) & $87(47.5)$ & $103(50.7)$ & 0.534 & 1.318 & $0.552-3.147$ \\
\hline $\begin{array}{l}\text { Bone mass below the expected } \\
\text { range for age ( }(\text { score } \leq-2), n(\%)\end{array}$ & $25(13.7)$ & 77 (37.9) & $<0.001$ & 3.361 & $1.682-6.717$ \\
\hline BASDAl, median (Q1-Q3) & $3.7(2.7-5.8)$ & $3.6(1.9-5.2)$ & 0.862 & 0.913 & $0.327-2.548$ \\
\hline BASFI, median (Q1-Q3) & $2.8(1.0-4.4)$ & $4.2(1.8-7.5)$ & 0.002 & 1.275 & $1.093-1.487$ \\
\hline TNF blockers >3 months, $\mathrm{n}(\%)$ & $16(8.7)$ & $42(20.7)$ & 0.031 & 2.614 & $1.092-6.259$ \\
\hline Continuous NSAIDs use, n (\%) & $38(20.8)$ & $32(15.8)$ & 0.195 & 0.621 & $0.302-1.277$ \\
\hline SSZ > 6 months, n (\%) & $41(22.4)$ & $55(27.1)$ & 0.276 & 1.283 & $0.819-2.009$ \\
\hline MTX >6 months, n (\%) & $14(7.7)$ & $26(12.8)$ & 0.112 & 1.513 & $0.908-2.521$ \\
\hline Thal >6 months, n (\%) & $15(8.2)$ & $16(7.9)$ & 0.891 & 1.097 & $0.292-4.123$ \\
\hline Glucocorticoid >2 weeks, n (\%) & $15(8.2)$ & $23(11.3)$ & 0.312 & 1.315 & $0.773-2.236$ \\
\hline
\end{tabular}

BASRI-hip: bath ankylosing spondylitis radiology hip index; OR: odds ratio; Cl: confidence interval; SD: standard deviation; BMI: body mass index; AS: ankylosing spondylitis; CRP: C-reactive protein; ESR: erythrocyte sedimentation rate; BASDAl: bath ankylosing spondylitis disease activity index; BASFI: bath ankylosing spondylitis functional index; TNF: tumor necrosis factor; NSAIDs: nonsteroidal anti-inflammatory drugs; SSZ: sulfasalazine; MTX: methotrexate; Thal: thalidomide.

Table 3. Multivariate regression analysis of potential factors associated with radiological hip joint involvement.

\begin{tabular}{l|c|c|c}
\hline Variables & $\mathrm{p}$ & Adjusted OR* & $95 \% \mathrm{Cl}$ \\
\hline Juvenile onset (onset age $\leq 16$ years) & 0.001 & 4.159 & $1.779-9.721$ \\
\hline $\mathrm{BMI}<18.5 \mathrm{~kg} / \mathrm{m}^{2}$ & 0.009 & 1.986 & $1.187-3.323$ \\
\hline Continuous NSAID use & 0.012 & 0.351 & $0.155-0.794$ \\
\hline Bone mass below the expected range for age (Z score $\leq-2)$ & 0.002 & 2.791 & $1.456-5.352$ \\
\hline BASFI & 0.006 & 1.382 & $1.097-1.741$ \\
\hline
\end{tabular}

OR: odds ratio; Cl: confidence interval; BMI: body mass index; NSAID: nonsteroidal anti-inflammatory drugs; BASFI: bath ankylosing spondylitis functional index. 


\section{DISCUSSION}

Our study indicated that that juvenile onset (age $\leq 16$ years), bone mass below the expected range for age $(Z$ score $\leq-2)$, and BMI $<18.5 \mathrm{~kg} / \mathrm{m}^{2}$ were independently associated with radiological hip joint involvement, with OR value of 4.159, 2.791, and 1.986, respectively.

Previous studies have already demonstrated that the juvenile onset is a risk factor for hip joint involvement in patients with AS. Patients with AS with juvenile onset might be associated with serious condition, the proportion of those with radiological hip joint damage was high, and the need for joint replacement surgery might be increased ${ }^{7}$. Patients with spondyloarthritis (when symptoms begin in childhood) were more likely to involve the hip joints or to induce cause attachment point inflammation, than to affect the axial bones ${ }^{8}$. Prior study demonstrated that the degree of radiological hip joint damage in patient with AS with juvenile onset was significantly more severe than those with adult onset, and rare patients with late-onset AS occurred with radiological hip joint damage ${ }^{9,10}$. These highlighted that patients with AS with juvenile onset were more prone to be involved with hip joint involvement. This patient population should be closely followed up and monitored for the progression of hip joint damage.

Patients with AS are more prone to be accompanied with low bone mass and/or osteoporosis ${ }^{11}$. Among all enrolled 386 patients with AS in our cross-sectional study, 102 (26.4\%) patients had bone mass below the expected range for age ( $Z$ score $\leq-2)$. The proportion of patients with bone mass below the expected range for age was $37.9 \%$ in patients with AS with radiological hip joint involvement, which was significantly higher than that $(13.7 \%)$ of those without it. Multivariate regression analysis further showed that bone mass below the expected range for age was independently associated with radiological hip joint involvement in patients with AS. The lower bone density in patients with AS with radiological hip involvement may be attributed to the changes of the body biomechanical mechanism influenced by hip joint damage. Decreased exercises bring about the increasing occurrence risk of osteoporosis, while exercise could induce osteoclast differentiation, trigger bone reconstruction, and increase the bone mass ${ }^{12}$.

Prior study indicated that high BMI and advanced hip arthritis at baseline were associated with hip joint replacement surgery in patients with $\mathrm{AS}^{13}$. In our study, 386 patients with AS showed a mean BMI of $22.96 \pm 4.38 \mathrm{~kg} / \mathrm{m}^{2}$, which was also lower than the mean value from Chinese adults $\left(\mathrm{BMI}=24.7 \pm 3.5 \mathrm{~g} / \mathrm{m}^{2}\right)^{14}$. Compared to healthy individuals, patients with $\mathrm{AS}$ were reported to have the fat free mass of about $3 \mathrm{~kg}$ lower than the mean value, and appendicular lean mass of $1 \mathrm{~kg} / \mathrm{m}$ less than the mean value ${ }^{15}$. Multivariate regression analysis further proved that $\mathrm{BMI}<18.5 \mathrm{~kg} / \mathrm{m}^{2}$ was an independent risk factor for radiological hip joint involvement in patients with AS.

In our study, cumulative use of slow-acting drugs, such as SSZ, MTX, and thalidomide for no less than 6 months was not the independently protective factor for radiological hip joint damage in patients with AS. However, a few studies considered that TNF blockers could slow the progression of hip joint damage in patients with $\mathrm{AS}^{16}$. A prior report with small sample size even observed increased hip joint space after TNF blocker treatment in six patients with AS accompanying radiological hip joint involvement, with their baseline BASRI score (3 points) returned to 2 points $^{17}$. Our study ruled out that the proportion of TNF blockers usage $>3$ months in patients with AS with radiological hip joint damage was $20.7 \%$, which was significantly higher than that $(8.7 \%)$ observed in those without it. Nevertheless, multivariate regression analysis indicated that TNF blockers $>3$ months is not a protective factor for radiological hip joint damage in patients with AS. Future longitudinal study might be required to explore the therapeutic effect of TNF blockers on radiological hip joint damage in patients with AS.

The encouraging efficacy of NSAIDs for the treatment of AS has been extensively verified in previous studies. The recent updated 2019 American College of Rheumatology guidelines on AS and nonradiographic axial spondyloarthritis recommended continuous applications of NSAIDs in patients with $\mathrm{AS}^{18}$. Treatment strategy with continuous use of NSAIDs was recommended in patients with AS without contradictions, which could help in decreasing the radiological progression of spine ${ }^{19}$, and this was consistent with the findings observed in our study. Notably, prior studies observed that continuous treatment with NSAIDs decreased the risk of fracture in patients with $\mathrm{AS}^{20}$.

This study also had some limitations. First, this is a single-center, cross-sectional study with small sample size. Second, although the assessment results were objected according to X-ray, only when patients with AS with hip joint damage in the advanced stage could be detected by plain radiography. Third, due to the retrospective study design, only routine laboratory indexes were available in the clinical practice.

\section{CONCLUSIONS}

Juvenile onset, lower BMI, and bone mass below the expected range for age were independently associated with radiological hip joint involvement in patients with AS. Patients with AS with these clinical characteristics should be screened and followed up for the occurrence or progression of their hip joint damage. Continuous NSAID use should be recommended if patients were without contraindications, which is considered a protective factor for radiological hip joint involvement in these population.

\section{AUTHORS" CONTRIBUTIONS}

All authors contributed equally to the manuscript. 


\section{REFERENCES}

1. Dean LE, Jones GT, MacDonald AG, Downham C, Sturrock RD, Macfarlane GJ. Global prevalence of ankylosing spondylitis. Rheumatology (Oxford). 2014;53(4):650-7. https://doi. org/10.1093/rheumatology/ket387

2. Wink F, Arends S, Maas F, Bootsma H, Griep EN, Bruyn GAW, et al. High prevalence of hip involvement and decrease in inflammatory ultrasound lesions during tumour necrosis factor- $\alpha$ blocking therapy in ankylosing spondylitis. Rheumatology (Oxford). 2019;58(6):1040-6. https://doi.org/10.1093/ rheumatology/key382

3. Tam LS, Gu J, Yu D. Pathogenesis of ankylosing spondylitis. Nat Rev Rheumatol. 2010;6(7):399-405. https://doi.org/10.1038/ nrrheum.2010.79

4. Cruyssen BV, Muñoz-Gomariz E, Font P, Mulero J, de Vlam K, Boonen $A$, et al. Hip involvement in ankylosing spondylitis: epidemiology and risk factors associated with hip replacement surgery. Rheumatology (Oxford). 2010;49(1):73-81. https:// doi.org/10.1093/rheumatology/kep174

5. Hanson A, Brown MA. Genetics and the causes of ankylosing spondylitis. Rheum Dis Clin North Am. 2017;43(3):401-14. https://doi.org/10.1016/j.rdc.2017.04.006

6. MacKay K, Brophy S, Mack C, Doran M, Calin A. The development and validation of a radiographic grading system for the hip in ankylosing spondylitis: the bath ankylosing spondylitis radiology hip index. J Rheumatol. 2000;27(12):286672. PMID: 11128678

7. Qian Q, Xu X, He H, Ji H, Zhang H, Ding Y, et al. Clinical patterns and characteristics of ankylosing spondylitis in China. Clin Rheumatol. 2017;36(7):1561-8. https://doi.org/10.1007/ s10067-017-3660-3

8. Colbert RA. Classification of juvenile spondyloarthritis: enthesitis-related arthritis and beyond. Nat Rev Rheumatol. 2010;6(8):477-85. https://doi.org/10.1038/nrrheum.2010.103

9. Chen HA, Chen CH, Liao HT, Lin YJ, Chen PC, Chen WS, et al. Clinical, functional, and radiographic differences among juvenile-onset, adult-onset, and late-onset ankylosing spondylitis. J Rheumatol. 2012;39(5):1013-8. https://doi. org/10.3899/jrheum.111031

10. O'Shea FD, Boyle E, Riarh R, Tse SM, Laxer RM, Inman RD. Comparison of clinical and radiographic severity of juvenileonset versus adult-onset ankylosing spondylitis. Ann Rheum Dis. 2009;68(9):1407-12. https://doi.org/10.1136/ard.2008.092304

11. Malochet-Guinamand S, Pereira B, Tatar Z, Tournadre A, Moltó $A$, Dougados $M$, et al. Prevalence and risk factors of low bone mineral density in spondyloarthritis and prevalence of vertebral fractures. BMC Musculoskelet Disord. 2017;18(1):357. https:// doi.org/10.1186/s12891-017-1718-7

12. Stout NL, Baima J, Swisher AK, Winters-Stone KM, Welsh J. A systematic review of exercise systematic reviews in the cancer literature (2005-2017). PM R. 2017;9(9S2):S347-S384 https://doi.org/10.1016/j.pmrj.2017.07.074

13. Jeong $H$, Eun $Y H$, Kim IY, Kim H, Lee J, Koh EM, et al. Characteristics of hip involvement in patients with ankylosing spondylitis in Korea. Korean J Intern Med. 2017;32(1):158-64. https://doi.org/10.3904/kjim.2015.229

14. Linderman GC, Lu J, Lu Y, Sun X, Xu W, Nasir K, et al. Association of body mass index with blood pressure among 1.7 million Chinese adults. JAMA Netw Open. 2018;1(4):e181271. https:// doi.org/10.1001/jamanetworkopen.2018.1271

15. El Maghraoui A, Ebo'o FB, Sadni S, Majjad A, Hamza T, Mounach A. Is there a relation between pre-sarcopenia, sarcopenia, cachexia and osteoporosis in patients with ankylosing spondylitis? BMC Musculoskelet Disord. 2016;17:268. https:// doi.org/10.1186/s12891-016-1155-z

16. Manica SR, Sepriano A, Pimentel-Santos F, Gouveia N, Barcelos A, Branco JC, et al. Effectiveness of switching between TNF inhibitors in patients with axial spondyloarthritis: is the reason to switch relevant? Arthritis Res Ther. 2020;22(1):195. https:// doi.org/10.1186/s13075-020-02288-8

17. Song R, Chung SW, Lee SH. Radiographic evidence of hip joint recovery in patients with ankylosing spondylitis after treatment with anti-tumor necrosis factor agents: a case series. J Rheumatol. 2017;44(11):1759-60. https://doi.org/10.3899/ jrheum. 161401

18. Ward MM, Deodhar A, Gensler LS, Dubreuil M, Yu D, Khan MA, et al. 2019 update of the American College of Rheumatology/ Spondylitis Association of America/Spondyloarthritis Research and Treatment Network Recommendations for the Treatment of Ankylosing Spondylitis and Nonradiographic Axial Spondyloarthritis. Arthritis Care Res (Hoboken). 2019;71(10):1285-99. https://doi.org/10.1002/acr.24025

19. Lage RC, Marques CDL, Oliveira TL, Resende GG, Kohem $C L$, Saad CG, et al. Brazilian recommendations for the use of nonsteroidal anti-inflammatory drugs in patients with axial spondyloarthritis. Adv Rheumatol. 2021;61(1):4. https://doi. org/10.1186/s42358-020-00160-6

20. Rustagi T, Drazin D, Oner C, York J, Schroeder GD, Vaccaro $A R$, et al. Fractures in spinal ankylosing disorders: a narrative review of disease and injury types, treatment techniques, and outcomes. J Orthop Trauma. 2017;31 Suppl 4:S57-S74. https://doi.org/10.1097/BOT.0000000000000953 